\title{
Three Cases of Acute Methyl Bromide Poisoning in a Seedling Farm Family
}

\author{
Yuko YAMANO ${ }^{1 *}$, Jun KAGAWA ${ }^{1}$, Sumiko ISHIZU $^{1}$ and Osamu HARAYAMA ${ }^{2}$ \\ ${ }^{1}$ Department of Hygiene and Public Health, Tokyo Women's Medical University, 8-1 Kawada-cho, Shinjuku-ku, \\ Tokyo 162-8666, Japan \\ ${ }^{2}$ Nagano Prefectural Suzaka Hospital (currently Harayama Kodomo Clinic)
}

Received March 26, 2001 and accepted July 31, 2001

\begin{abstract}
We encountered three patients (Patient I: 39-year-old man, Patient II: 34-year-old woman, and Patient III: 5-year-old girl) with acute methyl bromide poisoning, which had occurred as a result of exposure to the gas that leaked from methyl bromide cans stored in a warehouse of a seedling farm. Since all three patients exhibited almost the same initial symptoms, i.e., severe vomiting, tonic convulsions and clouding of consciousness, botulism was suspected at first. However, subsequent inquiry revealed that 27 cans of methyl bromide had been stored in the building that the patients lived in, and that the cans had been damaged a few days before the onset of the patients' illness by a thrashing machine that was being moved by them to another location. Inspection revealed that all the cans of methyl bromide had passed the expiry date and were corroded. Even though none of the cans had been used, three cans with a capacity of $750 \mathrm{~g}$ were found to be empty. Plasma bromide ion concentrations were determined to be high $(72.9 \mu \mathrm{g} / \mathrm{ml}, 67.8 \mu \mathrm{g} / \mathrm{ml}$ and $91.5 \mu \mathrm{g} / \mathrm{ml}$; normal level, <5 $\mu \mathrm{g} / \mathrm{ml})$, and acute methyl bromide poisoning was diagnosed 8 days after admission of the patients to the hospital. Hemodialysis (peritoneal lavage in the case of the child) was performed immediately, after which the plasma bromide ion concentrations returned to normal and the general condition of the patients gradually improved.
\end{abstract}

Key words: Methyl bromide poisoning, Diagnosis, Safety management, Hemodialysis

\section{Introduction}

In the past, methyl bromide poisoning was known to occur frequently in workers involved in the production of methyl bromide $^{1)}$, loading and unloading at harbors ${ }^{2,3)}$, and processes connected with grain imports ${ }^{4}$. In recent years, however, the incidence of acute poisoning has decreased as a result of streamlining of the aforementioned processes and improvement of the environment ${ }^{5)}$. However, methyl bromide poisoning still occasionally occurs in farmers (and their families) engaged in fumigation and disinfection of soil due, in part, to inappropriate and unsupervised handling of the chemical ${ }^{6-8)}$.

In this paper, we report on three members of a family

*To whom correspondence should be addressed. who developed methyl bromide poisoning, who first experienced symptoms suggestive of food poisoning, including severe vomiting and neurological symptoms such as convulsions. Botulism was suspected at first, but the test results for botulinum toxin were negative. Based on the findings at a subsequent oral inquiry and the high concentrations of bromide ions in the blood, methyl bromide poisoning was diagnosed, about one week after it occurred.

\section{Case History}

\section{Onset and clinical course}

On November 16, 1988, an event that first led to the suspicion of methyl bromide poisoning occurred in the household of a seedling farmer in Nagano, Japan.

Patient I (farmer, 39 years old), Patient II (wife of Patient 

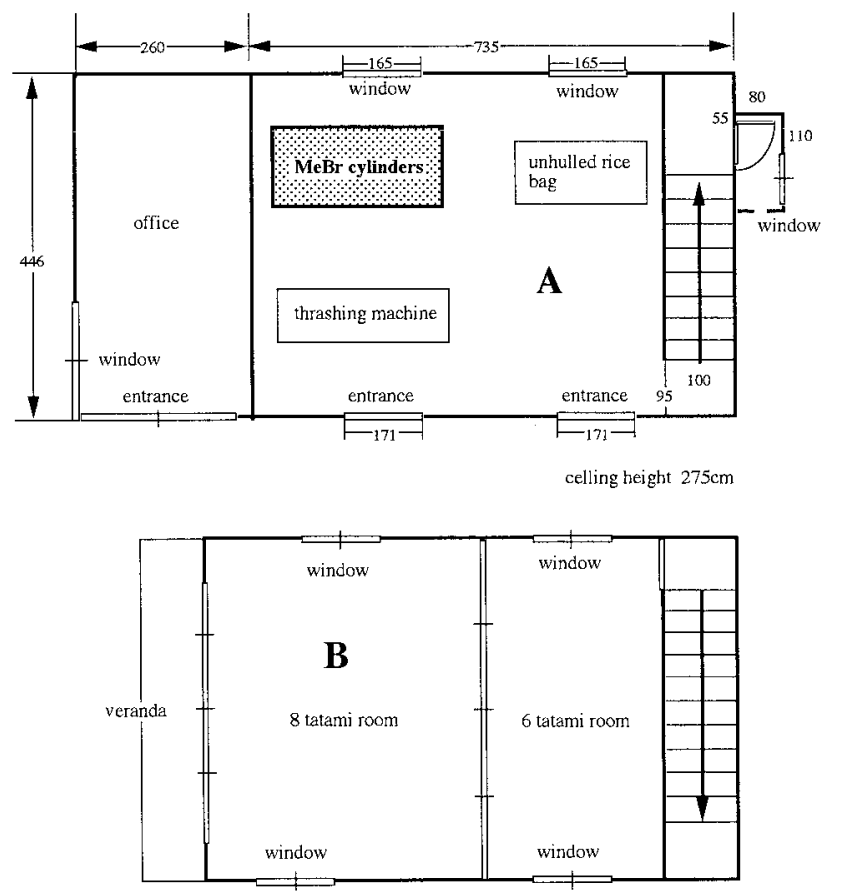

celling height $250 \mathrm{~cm}$

Fig. 1 Diagram of the warehouse.

A: The first floor was a warehouse in which the $\mathrm{MeBr}$ cylinders were stored. B: The second floor was the family living area. All the measurements are in centimeters.

I, 34 years old), and Patient III (daughter of Patient I and Patient II, 5 years old) lived on the second floor of a wooden warehouse used for storage of fertilizers and thrashing machines (Fig. 1-B floor).

On November 15, the day before the poisoning, all the three had gone to bed at 9:00 p.m. Between around 11:00 p.m. and 12:00 a.m., Patient III, followed by Patient II and then Patient I, experienced severe intermittent vomiting, which persisted until early dawn. The symptom then resolved slightly, and thinking that they had mild food poisoning, the family went back to sleep.

At around 7:00 a.m. on November 16, when Patient II attempted to get up, she felt severely dizzy and lay down again. Around 11:00 a.m., a family member living in a nearby building, wondering why patients I, II and III did not come down from the second floor till quite late, looked into their room on the second floor. The three patients were found in a state of akinetic mutism. They were immediately taken to a nearby clinic. Since all the three had severe vomiting, food poisoning was suspected at first. Patient III exhibited consciousness disturbance as well and had severe convulsions, and diagnosis and treatment by a pediatrician were considered necessary. Around 0:30 p.m. on the same day, therefore, she was transferred to the emergency department of the prefectural hospital.

Patients I and II were given symptomatic treatment and placed under observation; however, their symptoms did not improve. Thus, intensive care was judged to be necessary, and around 3:30 p.m. on the same day, they were also transferred to the emergency department of the same prefectural hospital.

\section{Case report}

Patient I: A 39-year-old male farmer.

He was admitted to the hospital because of vomiting and generalized tonic convulsions. On admission, he spoke clearly, but his hands and body were shaking, and he was restless. He also occasionally slipped into a state of akinetic mutism. Thus, his neurological and behavioral status were unstable. No significant laboratory abnormalities were noted on routine examination. Since the neurological and behavioral abnormalities improved on Day 2 of admission, the patient's history was taken again and his residence was inspected. On Day 8 of admission, methyl bromide poisoning was diagnosed. Hemodialysis was performed on Day 9. The bromide ion concentration, which was high in the plasma sample obtained immediately after admission on Day 1 (72.9 $\mu \mathrm{g} / \mathrm{ml}$ ), decreased to $6.6 \mu \mathrm{g} / \mathrm{ml}$ after the dialysis (Fig. 2), and the neurological and behavioral symptoms resolved. The patient was discharged on Day 18 of admission.

Patient II: A 34-year-old woman. (Wife of Patient I)

She was admitted to the hospital because of vomiting, generalized tonic convulsions and delirium. On admission, her eyes were fixed on one point, and she did not speak clearly. She did not respond when spoken to. Soon, she began to blink vigorously, repeating the motion of pointing to various parts of body, owing to pain. Thus, she was in a state of delirium. She also exhibited sialorrhea and tonic convulsions. Since the symptoms progressively worsened, she was transferred to the prefectural hospital at around 3:30 p.m. of the same day.

Results of laboratory examination at admission: No significant laboratory abnormalities were noted on routine examination. On Day 2 of admission, she exhibited abnormal behavior and ran into the room of Patient III (her daughter) with a queer cry. Like Patient I, she underwent hemodialysis on Day 9 of admission, after which the plasma bromide ion concentration, which was $67.8 \mu \mathrm{g} / \mathrm{ml}$ in the specimens obtained on Day 1 of admission, decreased to $7.3 \mu \mathrm{g} / \mathrm{ml}$. The convulsions subsided and her condition showed no special change. She was discharged on Day 27 of admission. 

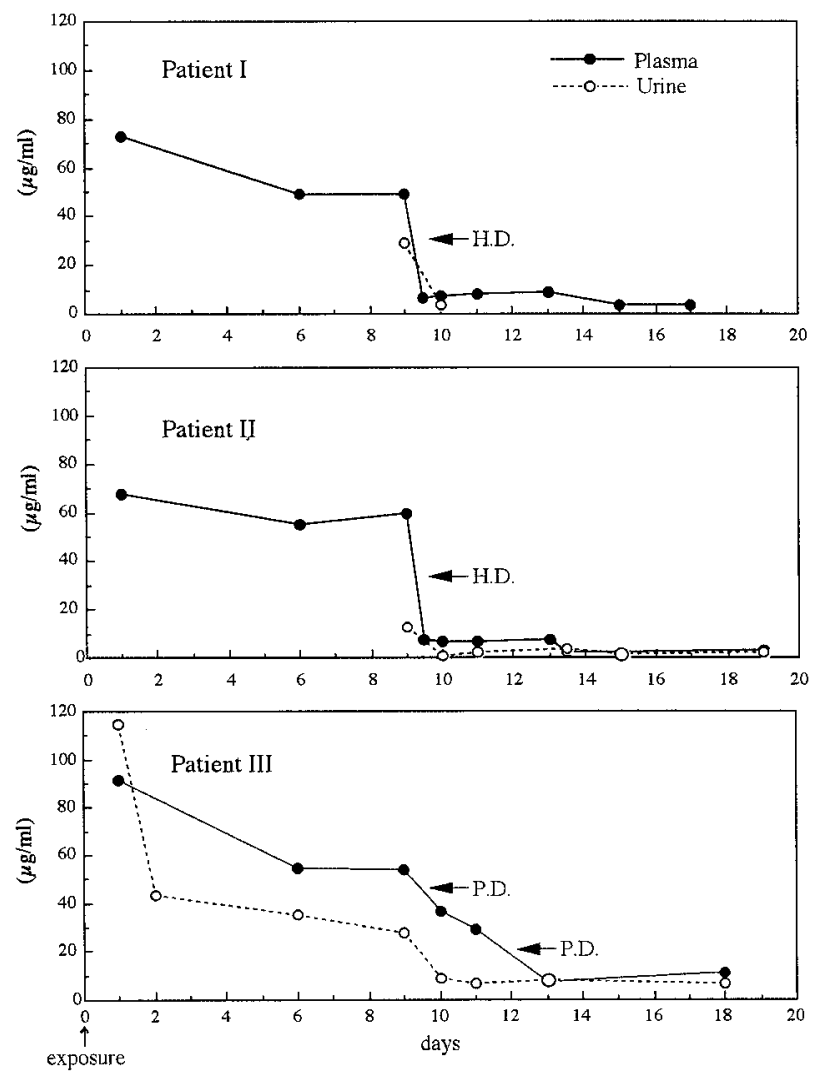

Fig. 2 Time course of changes in the bromide ion levels in the plasma and urine.

H.D.: hemodialysis, P.D.: peritoneal dialysis.

Patient III: A 5-year-old girl (daughter of Patients I and II)

She was admitted to the hospital because of vomiting, generalized tonic convulsions and clouding of consciousness. On admission, she exhibited severe vomiting. As the patient vomited repeatedly, maintenance fluids were administered to improve symptoms of dehydration. Vomiting subsequently improved, but clouding of consciousness and convulsions persisted, so the patient was transferred to the prefectural hospital around 12:30 p.m. the same day. Her complexion was normal. She did not respond when spoken to, but responded to pain, although equivocally. Her achilles and patella tendon reflexes were slow and the position and focus of the eyes were unstable, but the light reflex was normal. She occasionally moved all the four extremities without purpose. Choreoid movements of the fingers were observed. Her blood pressure was 113/62 mmHg on admission. Blood gas analysis revealed a state of respiratory alkalosis, with a $\mathrm{pH}$ of $7.506, \mathrm{PO}_{2}$ of $110.0 \mathrm{mmHg}, \mathrm{PCO}_{2}$ of $17.7 \mathrm{mmHg}$, and $\mathrm{HCO}_{3}$ of $13.9 \mathrm{mEq} / \mathrm{L}$. Blood examination revealed increases in the white blood cell count and serum LDH and BUN level (Table 1). Urinalysis showed no abnormal
Table 1. Laboratory data of Patient III

\begin{tabular}{|c|c|c|}
\hline Hamatology & & (normal range) \\
\hline WBC: & $21100 / \mu 1$ & $(4000-12000)$ \\
\hline RBC: & $508 \times 10^{4} / \mu \mathrm{l}$ & $(350-520)$ \\
\hline $\mathrm{Hb}:$ & $14.2 \mathrm{~g} / \mathrm{dl}$ & $(12.0-15.5)$ \\
\hline Ht: & $44.3 \%$ & $(36-45)$ \\
\hline PLT: & $23.4 \times 10^{4} / \mu \mathrm{l}$ & $(15-60)$ \\
\hline \multicolumn{3}{|c|}{ Biochemistry } \\
\hline TP: & $7.0 \mathrm{~g} / \mathrm{dl}$ & $(6.5-8.0)$ \\
\hline GOT: & $33 \mathrm{IU} / \mathrm{L}$ & $(5-35)$ \\
\hline GPT: & $13 \mathrm{IU} / \mathrm{L}$ & $(4-44)$ \\
\hline LDH: & $574 \mathrm{IU} / \mathrm{L}$ & $(107-220)$ \\
\hline ALP: & $27.4 \mathrm{KAU}$ & $(6.4-16.2)$ \\
\hline ChE: & $0.98 \Delta \mathrm{pH}$ & $(0.6-1.2)$ \\
\hline BUN: & $27.9 \mathrm{mg} / \mathrm{dl}$ & $(8-20)$ \\
\hline UA: & $8.1 \mathrm{mg} / \mathrm{dl}$ & $(2.4-5.9)$ \\
\hline Na: & $142 \mathrm{mEq} / \mathrm{L}$ & $(134-147)$ \\
\hline $\mathrm{K}:$ & $4.0 \mathrm{mEq} / \mathrm{L}$ & $(3.6-5.0)$ \\
\hline $\mathrm{Cl}:$ & $106 \mathrm{mEq} / \mathrm{L}$ & $(96-107)$ \\
\hline $\mathrm{Ca}:$ & $5.0 \mathrm{mEq} / \mathrm{L}$ & $(4.4-5.1)$ \\
\hline P: & $5.2 \mathrm{mg} / \mathrm{dl}$ & $(4.0-6.0)$ \\
\hline \multicolumn{3}{|c|}{ Arterial blood gas analysis } \\
\hline pH: & 7.506 & $(7.35-7.45)$ \\
\hline $\mathrm{PO}_{2}:$ & $110.0 \mathrm{mmHg}$ & $(95-100)$ \\
\hline $\mathrm{PCO}_{2}:$ & $17.7 \mathrm{mmHg}$ & $(35-45)$ \\
\hline $\mathrm{HCO}_{3}:$ & $13.9 \mathrm{mEq} / \mathrm{L}$ & $(22-26)$ \\
\hline
\end{tabular}

changes concerning urinary protein and hematuria. Maintenance fluids were administered and gastric lavage was performed, but the lavage yielded only gastric juice and a small amount of blood. Around 2:00 p.m. on Day 1 of admission, she had generalized tonic-clonic convulsions lasting for about a minute, controlled with an intravenous injection of $5 \mu \mathrm{g}$ of Horizon. Around 5:00 p.m. on the same day, she spoke relatively clearly and began to respond appropriately to pain. On Day 2 of admission, she responded to verbal commands, but was unable to assume a sitting position, and easily slipped back into a state of lethargy. On Day 3 of admission, she was able to eat meals in a sitting position using chopsticks, but she complained of lightheadedness, and she exhibited urinary and stool incontinence. On Day 4, she spoke clearly, but she was in a bad mood and tended to refuse everything. She complained of lightheadedness, but she was able to walk. On Day 5 of admission, she was in a state of lethargy, and she did not respond satisfactorily to verbal commands. Suddenly thereafter, she became delirious, hitting people and objects in the vicinity, laughing, and crying queerly. The bromide ion concentration in the plasma specimen obtained on Day 1 of admission was high $(91.5 \mu \mathrm{g} / \mathrm{ml})$. After methyl bromide poisoning 


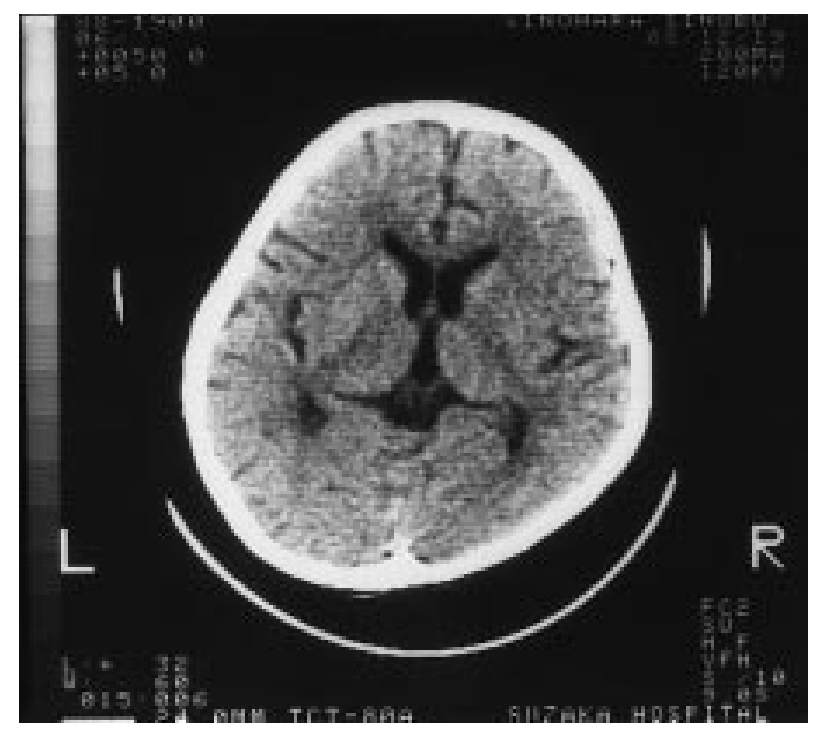

Fig. 3-a Brain CT of Patient III (as on admission). Enlargement of the brain sulci is observed.

was diagnosed, peritoneal lavage was performed twice, from Day 9 to Day 10, and Day 11 to Day 12 of admission, after which the plasma bromide ion concentration decreased to $7.5 \mu \mathrm{g} / \mathrm{ml}$ (Fig. 2). During this period, while her general condition stabilized, her aggressive behavior continued. The achilles and patella tendon reflexes remained slow. A brain CT performed on Day 34 of admission revealed enlargement of the brain sulci, and mild cerebral atrophy was suspected (Fig. 3-A). However, no remarkable symptoms were noted during the subsequent clinical course, and the patient was discharged on Day 42 of admission. A brain CT performed 3 months after the discharge revealed improvement (Fig. 3B). No memory impairment was noted.

\section{Discussion}

The initial symptoms of methyl bromide poisoning usually consist of such neurological symptoms as vomiting and convulsions, but they are often non-specific ${ }^{1,5,9,10)}$. It is therefore difficult to identify the causal relationship between the symptoms and methyl bromide poisoning without information on the use of or exposure to methyl bromide fumigators, or the patient's occupation. Moreover, no specific abnormalities in routine laboratory data are noted. The bromide ion concentration in biological samples must be determined for making a definitive diagnosis ${ }^{11}$.

In the present report, since three members of a family exhibited similar symptoms, including severe vomiting and neurological symptoms such as convulsions, botulism was

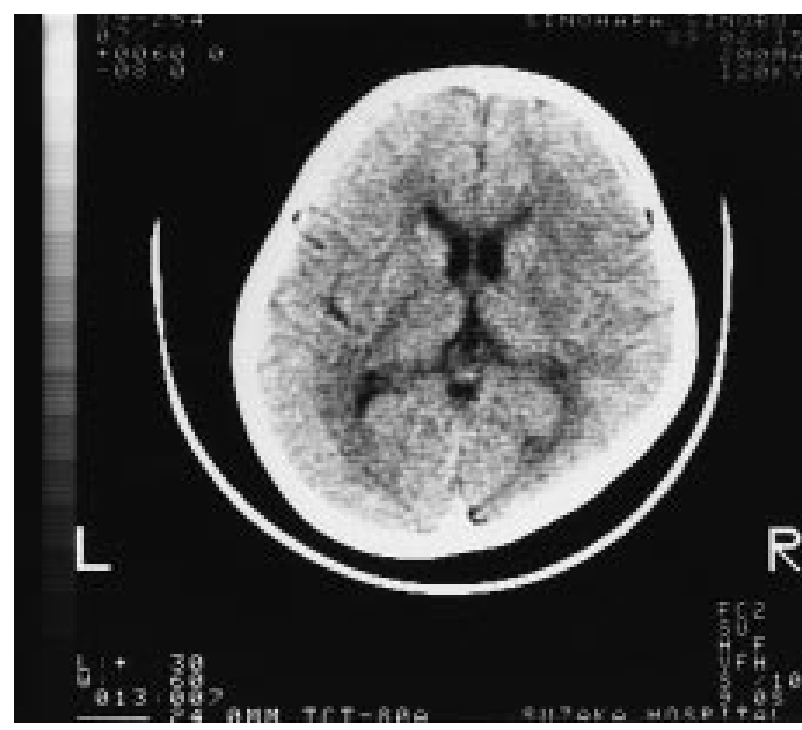

Fig. 3-b Brain CT of the same patient (3 months later). Improvement is noted, suggesting remission of the brain atrophy.

suspected at first, and the meal they ate the evening before the onset of the symptoms and the gastric aspirate obtained from Patient III were examined. Since the results of tests for botulinum toxin were negative, the first floor (Fig. 1-A floor) of the warehouse in which the patients were living (Fig. 1-B floor) was inspected on November 17 (Day 2 of admission), and a total of 27 cans containing methyl bromide were discovered. Three cans with a capacity of $750 \mathrm{~g}$ were empty; one can was found to contain only $350 \mathrm{~g}$. Since there were no signs suggesting that these cans had been used, leakage of the contents was suspected. When the can with only $350 \mathrm{~g}$ of methyl bromide was placed in a container filled with water, bubbles were noted, confirming leakage of methyl bromide gas. In other words, a total of approximately 2,650 g of methyl bromide was suspected to have leaked. About one year had passed since the date of expiry of all the cans, and the areas around the joints in the cans were found to have corroded.

According to the history provided by Patients I and II, they bumped against the methyl bromide cans while attempting to move the thrashing machine to the first floor of the warehouse (Fig. 1-A floor) on November 14. It is difficult to estimate the degree of exposure because many factors, including the hours of exposure and the route of dispersion in a wooden building, remain unknown. However, considering the fact that methyl bromide is present as a gas at ordinary temperatures under normal pressure, if about 2,650 $\mathrm{g}$ of methyl bromide had been released into the air all at once, the estimated exposure concentration would be 15.4 
$\mathrm{g} / \mathrm{m}^{3}$ ( $\fallingdotseq 4000 \mathrm{ppm}$ ). This is much higher than the TWA value of the acceptable concentration ( $5 \mathrm{ppm}$ ) during fumigation works designated by $\mathrm{ACGIH}^{12)}$. Thus, these patients were suspected to have inhaled a very high concentration of methyl bromide gas and developed poisoning. In support of this assumption, when bromide ion analysis ${ }^{11)}$ was conducted immediately in the biological samples obtained from the patients, all the three patients were found to have plasma bromide ion concentrations about 20 to 30 times higher (Patient I: $72.9 \mu \mathrm{g} / \mathrm{ml}$, Patient II: 67.8 $\mu \mathrm{g} / \mathrm{ml}$, and Patient III: $91.5 \mu \mathrm{g} / \mathrm{ml}$ ) than normal (3.7 \pm 1.5 $\mu \mathrm{g} / \mathrm{ml})^{11)}$. Moreover, the latency period of at least one day after the exposure (November 14) until the development of symptoms (dawn of November 16) ${ }^{1,2,9)}$, and the presence of neurological symptoms, including convulsions ${ }^{13-16)}$, are consistent with the characteristics of methyl bromide poisoning reported to date ${ }^{1,8,10,17)}$.

Thus, severe acute methyl bromide poisoning was diagnosed. Metabolic acidosis is often seen in the case of methyl bromide poisoning ${ }^{18)}$, but these patients were in a state of respiratory alkalosis believed that have been caused by hyperventilation accompanying vomiting, values normalized on Day 2 of admission and they did not present with acidosis. BUN was also slightly elevated, but there was no edema or increase in blood pressure and urinalysis was normal, so there was believed to be no abnormalities in renal function.

Symptomatic therapy is usually all that is required to treat methyl bromide poisoning ${ }^{1}$. In mild cases of poisoning, recovery can be expected with symptomatic therapy alone, even if the definitive diagnosis is delayed to some extent. However, oliguria or anuria may develop in serious cases, often associated with proteinuria and hematuria, and death may result ${ }^{1,8,19)}$. Therefore, the treatment of renal dysfunction or renal failure associated with the poisoning becomes the most important problem, and institution of dialysis in the early stages has been revealed to be life-saving ${ }^{5,19,20)}$. In our cases, definitive diagnosis was delayed, and hemodialysis (peritoneal lavage in the pediatric patient) was performed only on the ninth day after the occurrence of poisoning. Plasma bromide ion concentrations, which on the day before the dialysis were $49.5 \mu \mathrm{g} / \mathrm{ml}, 59.3 \mu \mathrm{g} / \mathrm{ml}$ and $53.7 \mu \mathrm{g} / \mathrm{ml}$ in Patients I, II and III, respectively, returned to nearly normal levels 11) $(6.6 \mu \mathrm{g} / \mathrm{ml}, 6.7 \mu \mathrm{g} / \mathrm{ml}$, and $7.5 \mu \mathrm{g} / \mathrm{ml}$, respectively) after the dialysis (peritoneal lavage in the child) (Fig. 2). Obvious improvement in the general condition of the patients was also noted after these procedures. While neurological sequelae were suspected at first in Patient III, her condition also eventually returned to normal, suggesting that the dialysis was effective in the treatment of acute methyl bromide poisoning.

As described above, in our cases, the cause of poisoning was difficult to identify because the exposure was not associated with the patients' occupation, but had resulted from inhalation of the gas leaked out from storage cans. Since the entire family was poisoned, it was impossible to immediately take a medical history. Botulinum food poisoning was suspected at first, because the initial symptoms were vomiting and neurological symptoms. A history was obtained only after the test results for botulinum toxin were found to be negative and the patients' symptoms stabilized. Inspection of the patients' residence, identification of the agricultural chemical, and confirmation with the manufacturer took some time, and it was only after these procedures were completed that the bromide concentrations in the biological samples were analyzed. It therefore took more than a week to make the diagnosis.

Thus, it would appear that while taking the history, attention should be directed not only to whether or not the patient is involved in occupations associated with exposure to methyl bromide, but also to the presence of storage cans containing the chemical in the vicinity.

\section{Acknowledgements}

We thank Ms. Tomoko Tokutake of the Department of Hygiene and Public health, Tokyo Women's Medical University, for her assistance in analyzing the bromide concentrations in the biological samples.

\section{References}

1) Ishizu $S$ (1989) Human toxicity of methyl bromide. In: Methyl bromide poisoning. ed. by Ishizu S, 26-98, Japan Fumigation Technology Association.

2) Yamano Y, Ishizu S, Kagawa J,Ohta K, Nuriya E (1994) Acute methyl bromide poisoning in the crew of imported timber carrier. J Science of Labour 70, 436-40.

3) Nakagawa M, Yasuhara T, Terai Y, Yoshino K, Fujimoto S, Kusaka N (1999) Two cases of methyl bromide poisoning. JJTOM 47, 652-5.

4) Deschamps FJ, Turpin JC (1996) Methyl bromide intoxication during grain store fumigation. Occup Med 46, 89-90.

5) Yamano Y, Ishizu S, Kagawa J (2000) Methyl bromide poisoning. Occup Health J 23, 18-23.

6) Hustinx WN, van de Laar RT, van Huffelen AC, Verwey JC, Meulenbelt J, Savelkoul TJ (1993) Systemic effects 
of inhalational methyl bromide poisoning: a study of nine cases occupationally exposed due to inadvertent spread during fumigation. Br J Ind Med 50, 155-9.

7) Langard S, Rognum T, Flotterod O, Skaug V (1996) Fatal accident resulting from methyl bromide poisoning after fumigation of a neighbouring house; leakage through sewage pipes. J Appl Toxicol 16, 445-8.

8) Ishizu S, Kato N, Morinobu S, Nagao N, Yamano Y, Ito I (1988) Cases of severe methyl bromide poisoning residing above a warehouse. Jpn J Ind Health 30, 5460.

9) Hine $\mathrm{CH}$ (1969) Methyl bromide poisoning. A review of ten cases. J Occup Med 11, 1-10.

10) Alexeeff GV, Kilgore WW (1983) Methyl bromide. Residue Rev 88, 101-53.

11) Yamano Y, Ito I, Nagao N, Ishizu S (1987) A simple determination method of bromide ion in plasma of methyl bromide workers by head space gas chromatography. Jpn J Ind Health 29, 196-201.

12) ACGIH (1999) TLVs and BEIs Threshold limit Values for Chemical Substances and Physical Agents and Biological Exposure Indices.

13) Uncini A, Basciani M, Di Muzio A, Antonio D, Onofrj M (1990) Methyl bromide myoclonus: an electrophysiological study. Acta Neurol Scand 81, 15964.
14) Obeso JA, Viteri C, Martinez Lage JM, Marsden CD (1986) Toxic Myoclonus. Adv Neurol 43, 225-30.

15) De Haro L, Gastaut JL, Jouglard J, Renacco E (1997) Central and peripheral neurotoxic effects of chronic methyl bromide intoxication. J Toxicol Clin Toxicol 35, 29-34.

16) Cavalleri F, Galassi G, Ferrari S, Merelli E, Volpi G, Gobba F, Del Carlo G, De Iaco A, Botticelli AR, Rizzuto N (1995) Methyl bromide induced neuropathy: a clinical, neurophysiological, and morphological study. J Neurol Neurosurg Psychiatry 58, 383.

17) Minami M, Hirata $Y$ (1986) Methyl bromide poisoning. J Nippon Med Sch 53, 129-36.

18) Satoh $S$, Watanabe $T$, Nakata $M$, Watanabe $S$, Itoh $Y$, Itoh T, Yamasita M, Shimazaki S, Naitoh Y (1980) Acute methyl bromide poisoning. The Japanese Journal of Acute Medicine 4, 1673-9.

19) Furukawa $T$, Shirai $T$, Fukutome $Y$, Shinohara $S$, Ida T, Matsui N, Fujiwara H, Tomura S, Takeuchi J (1985) A case of study on the Renal Associated with Severe Acute Methyl Bromide Intoxication. Inter Med 56, 56770.

20) Moosa MR, Jansen J, Edelstein CL (1994) Treatment of methyl bromide poisoning with haemodialysis. Postgrad Med J 70, 733-5. 